Article

\title{
Assay of Phospholipase D Activity by an Amperometric Choline Oxidase Biosensor
}

\author{
Rosanna Ciriello * and Antonio Guerrieri \\ Dipartimento di Scienze, Università degli Studi della Basilicata, Viale dell'Ateneo Lucano 10, 85100 Potenza, \\ Italy; antonio.guerrieri@unibas.it \\ * Correspondence: rosanna.ciriello@unibas.it; Tel.: +39-0971-205944
}

Received: 16 January 2020; Accepted: 25 February 2020; Published: 27 February 2020

\begin{abstract}
A novel electrochemical method to assay phospholipase D (PLD) activity is proposed based on the employment of a choline biosensor realized by immobilizing choline oxidase through co-crosslinking on an overoxidized polypyrrole film previously deposited on a platinum electrode. To perform the assay, an aliquot of a PLD standard solution is typically added to borate buffer containing phosphatidylcholine at a certain concentration and the oxidation current of hydrogen peroxide is then measured at the rotating modified electrode by applying a detection potential of $+0.7 \mathrm{~V}$ vs. SCE. Various experimental parameters influencing the assay were studied and optimized. The employment of $0.75 \%(\mathrm{v} / \mathrm{v})$ Triton X-100, $0.2 \mathrm{mM}$ calcium chloride, $5 \mathrm{mM}$ phosphatidylcholine, and borate buffer at $\mathrm{pH} 8.0$, ionic strength (I) $0.05 \mathrm{M}$ allowed to achieve considerable current responses. In order to assure a controlled mass transport and, at the same time, high sensitivity, an electrode rotation rate of $200 \mathrm{rpm}$ was selected. The proposed method showed a sensitivity of $24(\mathrm{nA} / \mathrm{s}) \cdot(\mathrm{IU} / \mathrm{mL})^{-1}$, a wide linear range up to $0.33 \mathrm{IU} / \mathrm{mL}$, fast response time and appreciable long-term stability. The limit of detection, evaluated from the linear calibration curve, was $0.005 \mathrm{IU} / \mathrm{mL}$ $(\mathrm{S} / \mathrm{N}=3)$. Finally, due to the presence of overoxidized polypyrrole film characterized by notable rejection properties towards electroactive compounds, a practical application to real sample analysis can be envisaged.
\end{abstract}

Keywords: choline biosensor; amperometric detection; overoxidized polypyrrole film; phospholipase D assay; phosphatidylcholine

\section{Introduction}

Phospholipase $\mathrm{D}$ (PLD) is a lipolytic enzyme which in vivo hydrolyses the terminal phosphodiester bond of phospholipids, generating phosphatidic acid (PA) and a free polar head group [1]. In addition, in the presence of a primary alcohol, it is able to catalyze the in vitro transphosphatidylation of the naturally abundant phosphatidylcholine [2]. PLD has been isolated and sequenced from a variety of sources and, as recently reviewed [3], can be regarded as a key component of many cellular and physiological processes.

In mammalian systems PLD is involved in cellular processes including membrane trafficking, cell proliferation, protein secretion, and metabolic regulation [1]. It has been associated with important pathological disorders such as thrombotic and neurodegenerative diseases, and several cancers [3]. Abnormalities in PLD activity in many human cancers have been noticed, highlighting a possible PLD role as a diagnostic biomarker and even as a target for drug discovery [4].

In plants, functional studies on PLD have shown its possible effects on membrane deterioration in response to stress injuries, senescence, aging, and pathogenesis [5].

In yeast, PLD activity has been shown to be involved mainly in sporulation and adaptation of nutrient utilization [6]. Bacterial PLD may act as virulence determinant and can mimic some reactions 
in cell [7]. Among hydrolytic enzymes from bacterial source, PLD from Streptomyces Chromofuscus is characterized by a notable transesterification capacity. This property can be exploited for the preparation of less abundant natural phospholipids, such as phosphatidylserine, phosphatidylglycerol, and novel artificial phospholipids of interest in the field of pharmaceutical and food industries, starting from crude or purified phosphatidylcholine [8,9]. Moreover, this bacterial PLD has been used as a model system for the mammalian enzyme since it mimics some reactions in cells [10]. A full understanding on the activation and inhibition mechanisms of this enzyme may be useful for in vivo studies on mammalian systems.

A wide variety of assay procedures have been realized for the determination of the activity of PLD enzymes. They can be substantially divided into two classes depending on the employment of exogenously-provided substrates, for in vitro measurements, or endogenous substrates for in vivo measurements [11]. In both cases the most used substrates are certainly radiolabeled phospholipids (radiolabeled acyl chains, phosphorus, or head group of the phospholipid). The radio-assay procedure has generally been reported to be fast and highly sensitive allowing to detect PLD in samples where its activity is very low, such as brain areas and peripheral tissues of mouse [12]. Despite these advantages, radio-assay is quite laborious and requires the employment of expensive and potentially health hazardous compounds.

Other methods have been proposed based on titrimetric or pH-stat techniques [13], chromatographic technique [14], conductimetry [15], infrared spectroscopy [16] and nuclear magnetic resonance [17]. These methods, while being viable alternatives to radio-assay, are not suited for routine analysis. In this context, enzyme coupled assays have gain increasing importance. They are based on the quantification of choline released during the hydrolysis of phosphatidylcholine by PLD. The released choline is measured by the formation of a colored or fluorescent complex, upon the sequential reactions of choline oxidase and peroxidase enzymes [18].

In order to bypass the requirement of coupled enzymes, synthetic substrates of PLD have been used such as phosphatidyl p-nitrophenol [19]. A graphene-based nano-assembly has been proposed as a fluorescence biosensor for sensitive detection of PLD activity by employing a fluorescein-labeled phospholipid [20]: even if quite interesting, since miming a cellular membrane, this approach requires labeling, a fluorescence assay and was not applied to any real sample where endogenous substances could generate fluorescence signals interfering with the PLD assay. Nanoprobes for fluorescence detection and imaging of PLD in cell lysate were also realized based as well on rhodamine B-labeled phospholipids [21,22].

Alternative spectrophotometric methods were based on the determination of phosphatidic acid through iron (III) complexation [23] or through $\mathrm{Ca}^{2+}$ complexation with 8-hydroxyquinoline [24]. In this last case, a direct and continuous PLD assay was achieved exploiting the chelation-enhanced fluorescence property of 8-hydroxyquinoline.

The aim of the present work was to realize an assay method sensitive, although nonradioactive, and easy to realize, without requiring the use of synthetic phospholipids, derivatization reaction, and instrumentations particularly expensive and difficult to handle. We developed an enzyme coupled procedure, based on a choline amperometric biosensor, able to provide real time measurements and suitable for high throughput assays. Indeed, electrochemical biosensors are clearly advantageous since they can overcome some limitations of the spectroscopic methods: they require a minimum sample pretreatment and can be used also for the analysis of turbid or colored samples.

The employment of choline amperometric biosensors for PLD assay is almost unexplored. Vrbova et al. [25] reported a PLD assay method based on a Clark-type electrode modified by a nylon net co-immobilizing choline oxidase and catalase. Besides the limitations typical of oxygen sensors, another drawback was surely the immobilization technique adopted which was quite complex and time consuming, requiring an incubation period of the enzymatic solution of 4 days.

The device we propose is surely easier to realize while assuring high enzyme stability. The approach we adopted is based on the detection of hydrogen peroxide which requires high applied potential 
thus causing severe interference problems from electroactive endogenous compounds presents in real samples. The modification of the Pt electrode by overoxidized polypyrrole, before choline oxidase (ChO) immobilization by co-crosslinking, could successfully solve this problem. This film is characterized by notable rejection properties towards interferents, as already demonstrated in the case of other enzymes and analytes [26-28].

The resulting device could be used in general to assay other enzymes than PLD which release choline as well. Indeed, we have already employed this biosensor to assay cholinesterase activity in human serum samples [29]. Having demonstrated the validity of such a sensor, in this work we wanted to extent its employment to the analysis of PLD by substantially modifying the reaction environment. Particularly, being PLD activity dependent on whether the substrate is readily accessible and on the presence of divalent cations at a certain concentration [3], a high sensor response was assured only upon having opportunely optimized the experimental conditions. As it will be shown, notable performances were achieved.

\section{Materials and Methods}

\subsection{Materials}

Choline oxidase (EC 1.1.3.17 from Alcaligenes species, $12 \mathrm{U} / \mathrm{mg}$ of solid), serum bovine albumin (fraction V), choline chloride, glutaraldehyde (grade II, $25 \%$ aqueous solution), L- $\alpha$-phosphatidylcholine (Type XI-E: from fresh egg yolk, approx. 99\%, $100 \mathrm{mg} / \mathrm{mL}$ solution in chloroform) and Triton X-100 were obtained from Sigma (Sigma Chemical Co.; St. Louis, MO, USA). Phospholipase D (EC 3.1.4.4., from Streptomyces Chromofuscus, 50,000 U/mL) was purchased from Biomol Research Laboratories Inc. (Butler Pike, Plymouth Meeting, PA, USA). Pig lung comes from a local butcher shop.

The above chemicals were of analytical reagent grade and were used without further purification with the exception of pyrrole (Aldrich, Steinheim, Germany) which was purified by distillation under vacuum by fixing the temperature at $62{ }^{\circ} \mathrm{C}$. Choline chloride before its use was left to dry in a vacuum desiccator for 3 days in the presence of $\mathrm{P} 2 \mathrm{O} 5$.

Choline stock solutions were prepared in double distilled-deionized water and stored in the dark at $4{ }^{\circ} \mathrm{C}$. Fresh L- $\alpha$-phosphatidylcholine standard solutions were prepared daily by evaporating chloroform and then dissolving the required amounts in $50 \mathrm{mM}$ borate buffer ( $\mathrm{pH} 8.0$ ) containing 0.75\% (v/v) Triton X-100 and $0.2 \mathrm{mM}$ calcium chloride. Phospholipase D solutions were prepared in borate buffer $\mathrm{pH} 8.0$ unless otherwise stated. The PLD activity is expressed in International Units (IU) (1 IU releases $1 \mu \mathrm{mol}$ of choline per minute) throughout the work.

\subsection{Spectrophotometric Assay}

Before use, PLD activity was assayed by an established colorimetric method using a reagent kit available from Biomol (Phospholipase D Assay Catalog SE-301). The assay comprises three reaction steps. In the first step, PLD catalyzes the hydrolysis of phosphatidylcholine to choline and phosphatidic acid. In the second step, the oxidation of choline catalyzed by choline oxidase produces two hydrogen peroxides. Peroxidase catalyzes the third step, in which the two hydrogen peroxides, phenol and 4-aminoantipyrine react to produce a quinonimine dye, with a millimolar extinction coefficient of $12.2 \mathrm{mM}^{-1} \mathrm{~cm}^{-1}$ at $500 \mathrm{~nm}$. Measurement of the absorbance at $500 \mathrm{~nm}$ can then be used to calculate the amount of choline produced by the phospholipase reaction.

\subsection{Apparatus}

To perform electrochemical experiments, an EG\&G (Princeton Applied Research, Princeton, NJ, USA) model 263 A potentiostat/galvanostat was used. Data acquisition was accomplished through a M270 electrochemical research software (EG\&G) version 4.23.

A conventional three electrode cell was used consisting of a platinum counter electrode and a saturated calomel reference electrode (SCE). The working electrode was a platinum disk $(2 \mathrm{~mm}$ 
diameter) embedded in a poly(tetrafluoroethylene) (PTFE) body. Experiments under controlled mass transport were performed by a CTV101 Speed Control Unit, EDI 101 Rotating Disc Electrode (RDE) (Radiometer Copenhagen). A rotation rate of $200 \mathrm{rpm}$ was typically adopted unless otherwise stated.

Spectrophotometric measurements were performed using a single beam LKB Biochrom Ultrospec II 4050 UV/Visible spectrophotometer (Biochrom Ltd., Cambridge, UK).

\subsection{Biosensor Preparation}

In order to assure a reproducible electrode surface, before each modification $\mathrm{Pt}$ substrates were subjected to a cleaning procedure comprising a first step of dipping in hot nitric acid for few minutes. Then the electrode was polished by mechanical abrasion employing an alumina slurry with particles of $0.05 \mu \mathrm{m}$. Finally, to remove any adsorbed alumina, the electrode was copiously rinsed with bi-distilled water and sonicated for several minutes.

Polypyrrole films (PPy) were electrosynthesized potentiostatically using a $0.4 \mathrm{M}$ pyrrole solution in $0.1 \mathrm{M} \mathrm{KCl}$ electrolyte. A selected potential of $+0.7 \mathrm{~V}$ versus SCE was applied and polymer growth was stopped when a deposition charge of $300 \mathrm{mC} / \mathrm{cm}^{2}$ was passed. The formed film was then immersed in a phosphate buffer $(\mathrm{pH}=7.0, \mathrm{I}=0.1 \mathrm{M})$ and overoxidized by applying a fixed potential of $+0.7 \mathrm{~V}$ versus SCE. After a time of at least $7 \mathrm{~h}$, a steady-state background current was reached and the overoxidation process was stopped. The resulting modified electrode ( $\mathrm{Pt} / \mathrm{PPyox}$ ) was rinsed with bi-distilled water and air-dried at room temperature before enzyme immobilization.

Choline oxidase immobilization was carried out by following a procedure already reported [30]: $16 \mathrm{mg}$ of bovine serum albumin (BSA) and $1 \mathrm{mg}$ of $\mathrm{ChO}$ were dissolved in $300 \mu \mathrm{L}$ of a phosphate buffer solution $(\mathrm{I}=0.1 \mathrm{M}, \mathrm{pH}=6.5) ; 30 \mu \mathrm{L}$ of $2.5 \%$ glutaraldehyde solution $(25 \%$ glutaraldehyde solution diluted 1:10 with phosphate buffer) were then added; $3 \mu$ of the resulting solution were pipetted onto the Pt/PPyox working electrode surface and spread out to completely cover the electrode surface avoiding air bubble formation. Finally, the modified electrode was air-dried at room temperature and soaked in the background electrolyte to remove weakly bound or adsorbed enzyme. The enzyme electrode was stored in phosphate buffer, $\mathrm{pH} 6.5, \mathrm{I} 0.1 \mathrm{M}$, at $4{ }^{\circ} \mathrm{C}$ in the dark.

\subsection{Electrochemical Measurement}

A detection potential of $+0.7 \mathrm{~V}$ versus SCE was adopted to perform all the electrochemical measurements. PLD assay was performed through batch addition experiments: the modified electrode was immersed in a borate buffer $(I=0.05 \mathrm{M}, \mathrm{pH}=8.0)$ solution stirred at $200 \mathrm{rpm}$ and containing calcium chloride $0.2 \mathrm{mM}$ and Triton X-100 0.75\% (v/v); an aliquot of a phosphatidylcholine solution, and then an aliquot of a standard PLD solution were added into the cell and the current variation with time was recorded. A temperature of $37^{\circ} \mathrm{C}$ was maintained for the duration of the assay by a thermostatic bath.

\subsection{Real Sample Analysis}

Extraction of PLD from pig lung was performed accordingly to a procedure described elsewhere [31]. Briefly, about $500 \mathrm{~g}$ of pig lung was minced and homogenized in sucrose buffer at $4{ }^{\circ} \mathrm{C}$, centrifuged and stored at $-80{ }^{\circ} \mathrm{C}$ until its use. Just before analysis, the thawed homogenized was diluted in buffer to reach the desired PLD activity, stirred, further centrifuged, and the desired supernatant aliquot was added to the electrochemical cell for PLD assay.

\section{Results and Discussion}

In the present work, we have proposed an assay method based on the employment of a modified $\mathrm{Pt} / \mathrm{PPyox} / \mathrm{ChO}$ electrode, realized following the fabrication steps shown in Scheme 1, which is immersed in a thermostated solution of phosphatidylcholine and kept under a fixed rotation rate. Then, to perform the assay, an aliquot of a standard PLD solution is injected in the cell which causes the release of free choline (Ch). The immobilized $\mathrm{ChO}$ catalyzes the oxidation of $\mathrm{Ch}$ to betaine with the subsequent 
production of hydrogen peroxide. At the electrode surface, opportunely polarized, hydrogen peroxide undergoes progressive oxidation producing a current signal which increases linearly with time. PLD activity in the cell solution can be evaluated from the slope of the current signal increase, as shown in Scheme 1, after having opportunely calibrated the sensor.

Following are the reactions involved to produce the sensor response

$$
\begin{gathered}
\text { phosphatidylcholine }+2 \mathrm{H}_{2} \mathrm{O} \stackrel{P L D}{\rightarrow} \text { phosphatidic acid }+ \text { choline } \\
\text { choline }+2 \mathrm{O}_{2}+\mathrm{H}_{2} \mathrm{O} \stackrel{\mathrm{ChO}}{\rightarrow} \text { betaine }+2 \mathrm{H}_{2} \mathrm{O}_{2} \\
\qquad \mathrm{H}_{2} \mathrm{O}_{2} \rightarrow \mathrm{O}_{2}+2 \mathrm{H}^{+}+2 \mathrm{e}^{-}
\end{gathered}
$$

A)

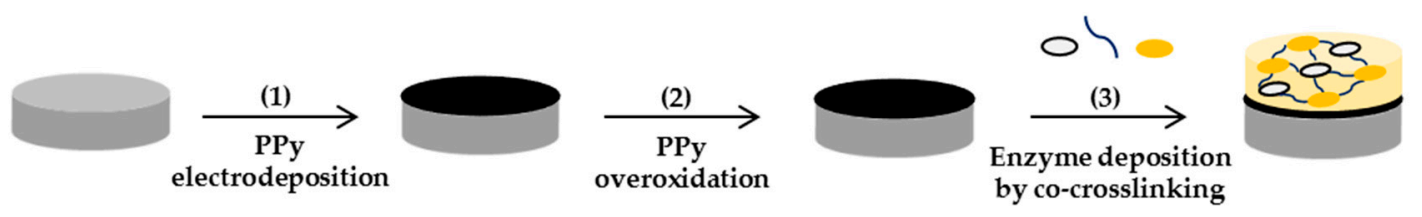

Pt electrode;

Polypyrrole (PPy);

Choline Oxidase; $\bigcirc$ Bovine Serum Albumine; ح Glutaraldehide

B)

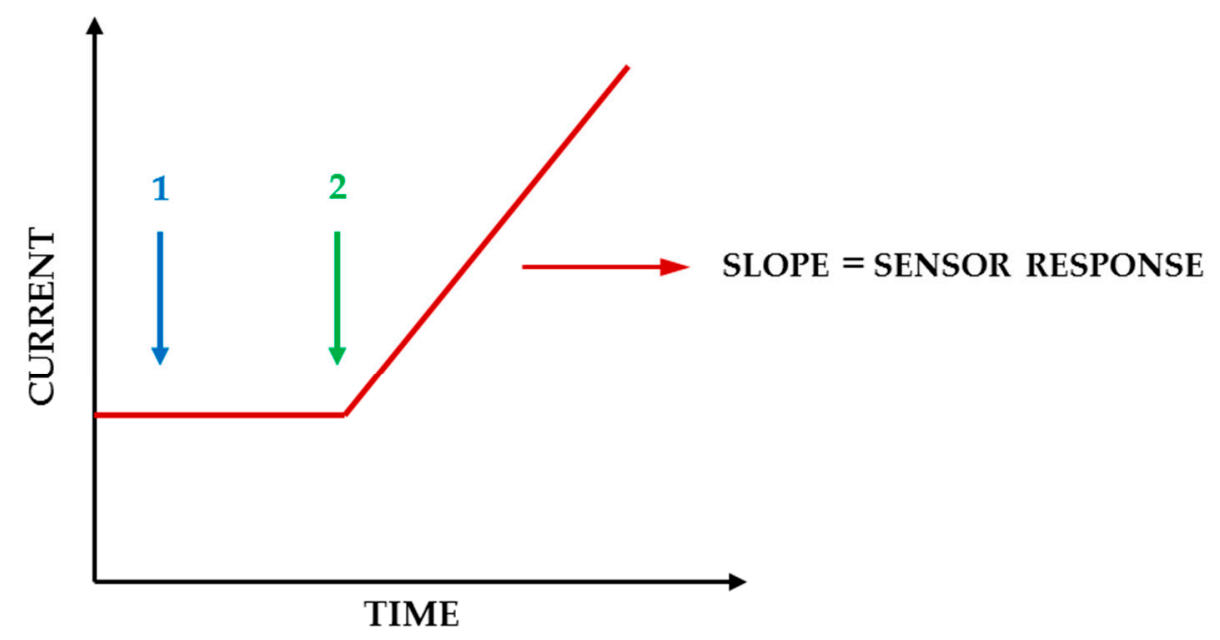

\section{PHOSPHATIDYLCHOLINE INJECTION}

\section{PLD INJECTION}

Scheme 1. Fabrication steps of the biosensor (A) and current signal acquisition (B).

PLDs from the culture broth of Streptomyces are commercially available or can be prepared by fermentation from some Actinomycetes strains [36,37]. Imamura and Horiuti provided information on the purification of PLD from Streptomyces Chromofuscus secreted into the growth medium [38]. They partially characterized this bacterial PLD furnishing a molecular weight of $57 \mathrm{kDa}$ and an isoelectric point of $\mathrm{pH}$ 5.1. To optimize the enzymatic reaction, alkaline $\mathrm{pH}$ values are required in the range 8-9 and the presence of detergent (Triton $\mathrm{X}-100$, deoxycholate), $\mathrm{Ca}^{2+}$ or both of them revealed able to significantly increase the velocity [38]. Indeed, like the eukaryotic enzymes PLD from Streptomyces Chromofuscus requires $\mathrm{Ca}^{2+}$ ion for activity whereas, unlike other phospholipases, does not exhibit "interfacial activation" or "surface dilution" [39,40]. This means that this enzyme does not 
show preference for substrate in the form of micellar short chain phospholipids rather than monomeric ones [39] and its specific activity does not depend on the mole fraction of substrate in a micelle or bilayer surface [40]. Nevertheless, considering that the catalytic reaction involves vesicle substrates, the transfer of PLD from aqueous solution to the lipid-water interface is a required step for the reaction to take place.

The notable performances of the choline oxidase biosensor towards choline detection have already been summarized in our previous work [29]. Fast response time, high sensitivity, wide linear range, and significant long-term stability were achieved. Furthermore, the presence of the underlying overoxidized polypyrrole film guaranteed a notable rejection of interferent compounds, electroactive at the high overpotential required to detect $\mathrm{H}_{2} \mathrm{O}_{2}$, thus allowing the application of the sensor to assay Cholinesterase in real samples as complex as human serum [29]. Electrochemical, XPS, and ESEM characterizations of these biosensors were already described elsewhere [28-30,32-35]. Based on these important achievements, in the present work we wanted to employ such a biosensor to develop a novel PLD assay method.

The binding mechanism that has been proposed for the enzyme is a two-step ping-pong like ordered one: the substrate combines with the enzyme giving a covalent phosphatidyl-enzyme moiety with release of choline; then, water attacking to the covalent adduct induces the release of phosphatidic acid [41]. The cleavage of the P-O bond is caused by the nucleophilic attack of water on the distal phosphate ester bond. It is worth noting that, in the presence of a primary alcohol at a high concentration, the phosphatidyl-enzyme intermediate can be decomposed to a different phospholipid.

It is evident that PLD activity is affected by various experimental variables, such as substrate accessibility, presence of a bication at a proper concentration, and a surfactant able to solubilize at the right extent the substrate, which need a careful investigation in addition to the more usual $\mathrm{pH}$ and composition of the reaction medium. An optimization study of the reaction conditions has therefore been carried out with the aim to implement a method able to quantify low PLD activities in a reproducible way and without any interference.

\subsection{Influence of Surfactant}

Phospholipases are generally more active on liposomes, mixed micellar deriving from the dispersion of phospholipids substrate in detergents, or phospholipids solubilized in organic solvents [42]. Particularly, PLD from Streptomyces Chromofuscus is reported to exhibit higher activity towards monomers and mixed micelles than substrate present in lipid vesicles [43]. When assaying PLD activity it is then a common practice to employ mixtures of phospholipid and detergents. PLDs from different sources are activated by anionic or neutral detergents [44] whose influence on the enzymatic activity has been attributed mainly to the micellization of phospholipids substrates. Changes of the physicochemical properties of the phospholipid bilayers are not to be excluded. Practically, detergents exert their action by destroying liposome structure favoring the gradual formation of mixed micelles. Indeed, the formation of mixed micelles is the final goal achieved during the interaction of detergents with liposome. At the beginning of such an interaction, surfactant monomers are incorporated within the lipid bilayer and, as a consequence, vesicle dimensions increase. Then, as the surfactant concentration is increased, phospholipids solubilization gradually occurs and liposomes along with mixed micelles are both presents. Finally, only mixed micelles are present as phospholipids are completely solubilized.

Triton X-100 is one of the most common surfactants employed for PLD assay. It is a non-ionic detergent with an average length of approximately 9.5 oxyethylene units per detergent molecule. Its wide employment can be justified considering that it is a mild non-denaturing detergent: even at concentrations up to $0.5 \%$ it usually does not damage most enzymes. For lysing cells lower concentrations of about $0.1 \%$ are sufficient.

In the present work, the appropriate Triton X-100 concentration to employ for PLD assay has been evaluated. At this aim experiments have been carried out by varying the detergent concentration in 
the range $0.1-0.9 \%(\mathrm{v} / \mathrm{v})$, while fixing the other experimental conditions close to the values adopted in the spectrophotometric assay (phosphatidylcholine $5 \mathrm{mM}$, PLD $0.22 \mathrm{IU} / \mathrm{mL}$, calcium chloride $10 \mathrm{mM}$, Tris buffer $\mathrm{pH}$ 8.0, I $0.05 \mathrm{M}$ ). In Figure 1 the variation of the slopes computed from the current signals increments is illustrated as a function of the detergent concentration. As it can be seen, in the first part of the graph biosensor response increases as detergent concentration is increased in agreement with a more efficient phosphatidylcholine dissolution at higher contents of Triton X-100. The graph shows a maximum located at a concentration of about $0.75 \%$. A further increase in detergent concentration probably causes a partial enzyme denaturation thus justifying the response decrease evidenced in the second part of the graph.

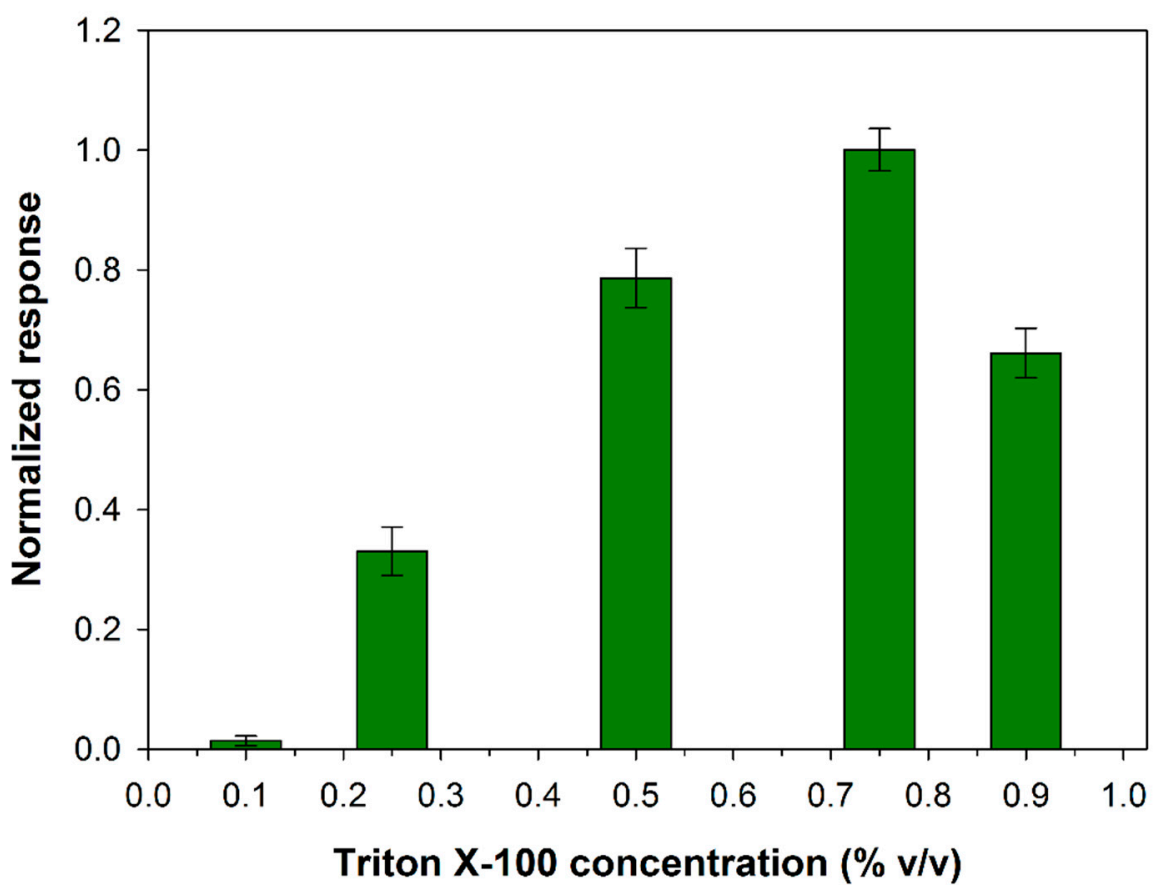

Figure 1. Normalized response (i.e., response/maximum response) of a typical $\mathrm{Pt} / \mathrm{PPyox} / \mathrm{ChO}$ biosensor to PLD $0.22 \mathrm{IU} / \mathrm{mL}$ as a function of Triton X-100 concentration. Supporting electrolyte: Tris buffer $\mathrm{pH}$ 8.0, I $0.05 \mathrm{M}$ containing $10 \mathrm{mM}$ calcium chloride, and $5 \mathrm{mM}$ phosphatydylcholine. Electrode rotation rate: $1000 \mathrm{rpm}$.

Indeed, many enzymes remain active in the presence of Triton X-100 even at concentration of $1 \%$, as it was reported for $\mathrm{ChO}$ [45]. As concern the effect of detergent on the activity of PLD, it was showed that when the activity was maximally increased by $\mathrm{Ca}^{2+}(10 \mathrm{mM})$ detergent was inhibitory at lower concentrations (completely at about $0.8 \mathrm{mM}$ ) and stimulating at higher concentrations (maximally at $4.5 \mathrm{mM}$ ) [38]. At the experimental conditions we adopted an inhibition effect on PLD from detergent is to be excluded. On the other hand, it was reported that the enzymatic reaction rate is optimal at a certain detergent to phospholipid ratio, a further increase in the molar ratio of Triton X-100 to phospholipid lead to progressive decrease in the enzymatic activities probably due to a sort of dilution of the micellar surface concentration of phosphatidylcholine [38]. In conclusion, the effect of the detergent on Phospholipase D activity would seem to be related essentially to the formation of mixed micelles that in the present experimental conditions is favored at a Triton concentration of $0.75 \%$. This value was adopted from now on to assay PLD activity.

\subsection{Influence of Calcium Concentration}

The PLD from S. Chromofuscus is a water-soluble enzyme unlike its natural substrate which forms macromolecular associations. Since the PLD activity takes place in a heterogeneous medium, factors 
that could enhance enzyme removal from the soluble part of the medium (i.e. aqueous solution) to the particulate part (i.e. the lipid vesicles or monolayer) are of relevance. At this aim, ultrafiltration experiments showed that $\mathrm{Ca}^{2+}$ at micromolar concentration levels was essential for the PLD binding to PC vesicles suggesting that the binding of $\mathrm{Ca}^{2+}$ to PLD is followed by a conformational change of PLD and then the enzyme likely associates with PC vesicles [46]. Besides favoring the enzyme location at the water-lipid interface, calcium ion is reported to increase also the catalytic activity of PLD: it plays a key role in the phosphatidyl enzyme geometry for the nucleophilic attack of water on the P-O bond [47]. Considering then the PLD requirement for calcium, experiments were performed to determine the extent to which added $\mathrm{Ca}^{2+}$ affects its activity. Figure 2 shows the influence of calcium content on the biosensor response at fixed phosphatidylcholine and PLD concentrations. As it is possible to see, PLD activity increases as calcium concentration is increased up to a maximum at about $0.2 \mathrm{mM}$ $\left(\log \left[\mathrm{Ca}^{2+}\right]=-0.7\right)$ and then decreases to reach a quite constant value from calcium concentrations higher than $1 \mathrm{mM}$.

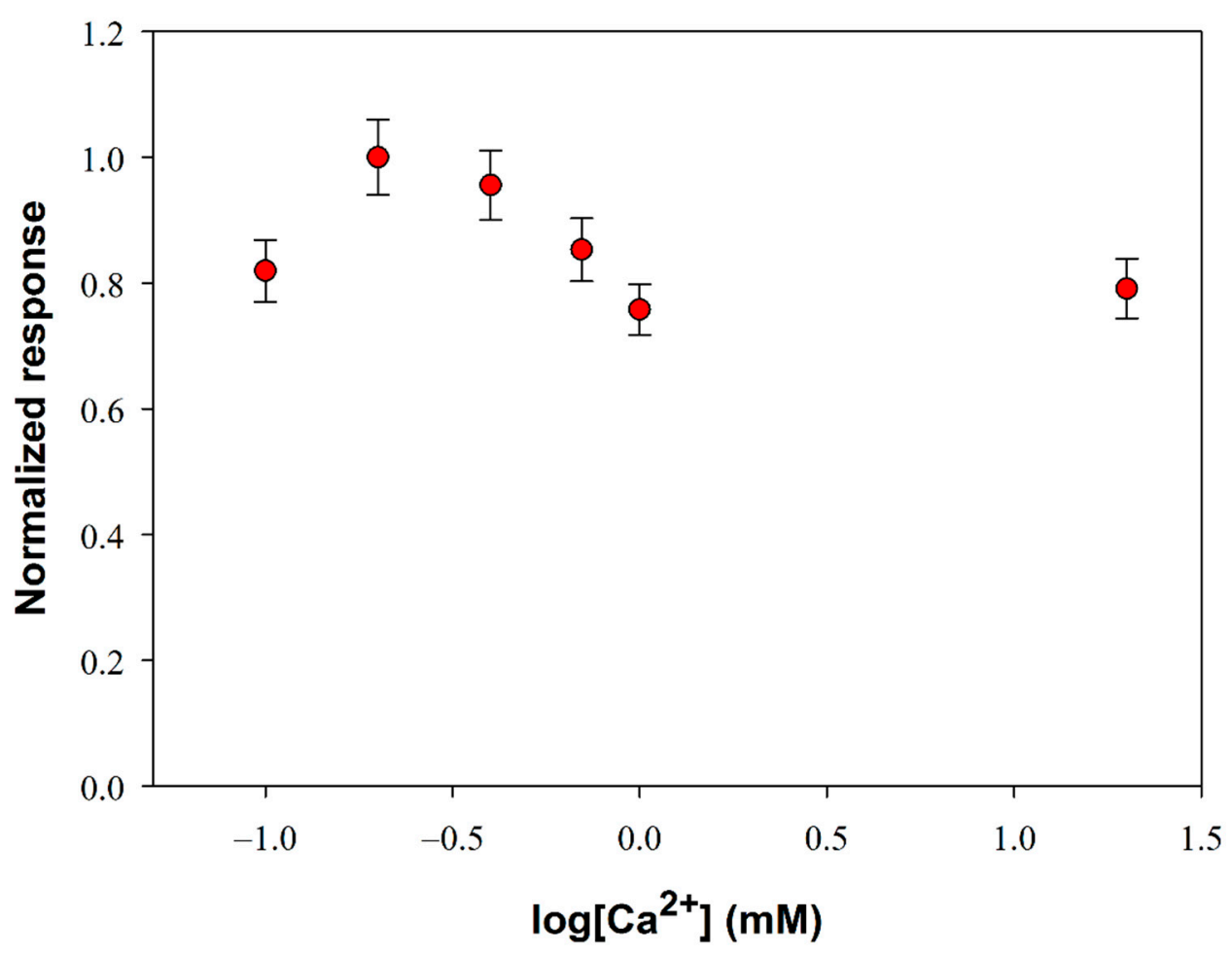

Figure 2. Normalized response (i.e., response/maximum response) of a typical $\mathrm{Pt} / \mathrm{PPyox} / \mathrm{ChO}$ biosensor to PLD $0.22 \mathrm{IU} / \mathrm{mL}$ as a function of $\mathrm{Ca}^{2+}$ concentration. Supporting electrolyte: Tris buffer $\mathrm{pH}$ 8.0, I $0.05 \mathrm{M}$ containing $0.75 \%(\mathrm{v} / \mathrm{v})$ Triton $\mathrm{X}-100$ and $5 \mathrm{mM}$ phosphatidylcholine. Electrode rotation rate: $1000 \mathrm{rpm}$. Each value represents the mean of triplicate measurements; the error bars represent the relevant standard deviations.

It is worth noting that, despite the small variations, an ANOVA analysis of data points (F-value 10.6, $p$-value 0.0004373 at a confidence level of $95 \%$ ) evidenced that there's a significant difference between the mean response values of Figure 2. A more detailed treatment of the ANOVA analysis is reported in the Supplementary Materials. A calcium concentration value of $0.2 \mathrm{mM}$ was therefore employed in the following experiments to optimize PLD assay.

\subsection{Influence of Electrode Rotation Rate}

The influence of substrate mass transport on the analytical performances of the biosensor was investigated. This study has been carried out in Tris- $\mathrm{HCl}$ buffer ( $\mathrm{pH}$ 8.0, I $0.05 \mathrm{M}$ ) containing Triton $\mathrm{X}-100$ and $\mathrm{Ca}^{2+}$ at the optimized concentrations respectively of $0.75 \%(\mathrm{v} / \mathrm{v})$ and $0.2 \mathrm{mM}$. Under these 
experimental conditions, the variation of the slope of the signal current upon the enzymatic conversion of phosphatidylcholine $5 \mathrm{mM}$ from PLD $0.22 \mathrm{IU} / \mathrm{mL}$ has been measured, by varying the rotation rate of the electrode from 50 to $3000 \mathrm{rpm}$. The upper limit of the explored range was limited by the well-known tendency of detergents to skim. Figure 3 shows the signal slopes variation as a function of the rotation rate at a Pt/PPyox/ChO biosensor. As expected in the case of a process limited by the mass transport in solution, the profile acquired shows in the first part an increment of the response as rotation rate is increased up to about $200 \mathrm{rpm}$. At higher rotation rates the slope of the signal decreases as rotation rate is increased, thus suggesting that the system is passing from an external diffusive control to an enzymatic kinetic control [48].

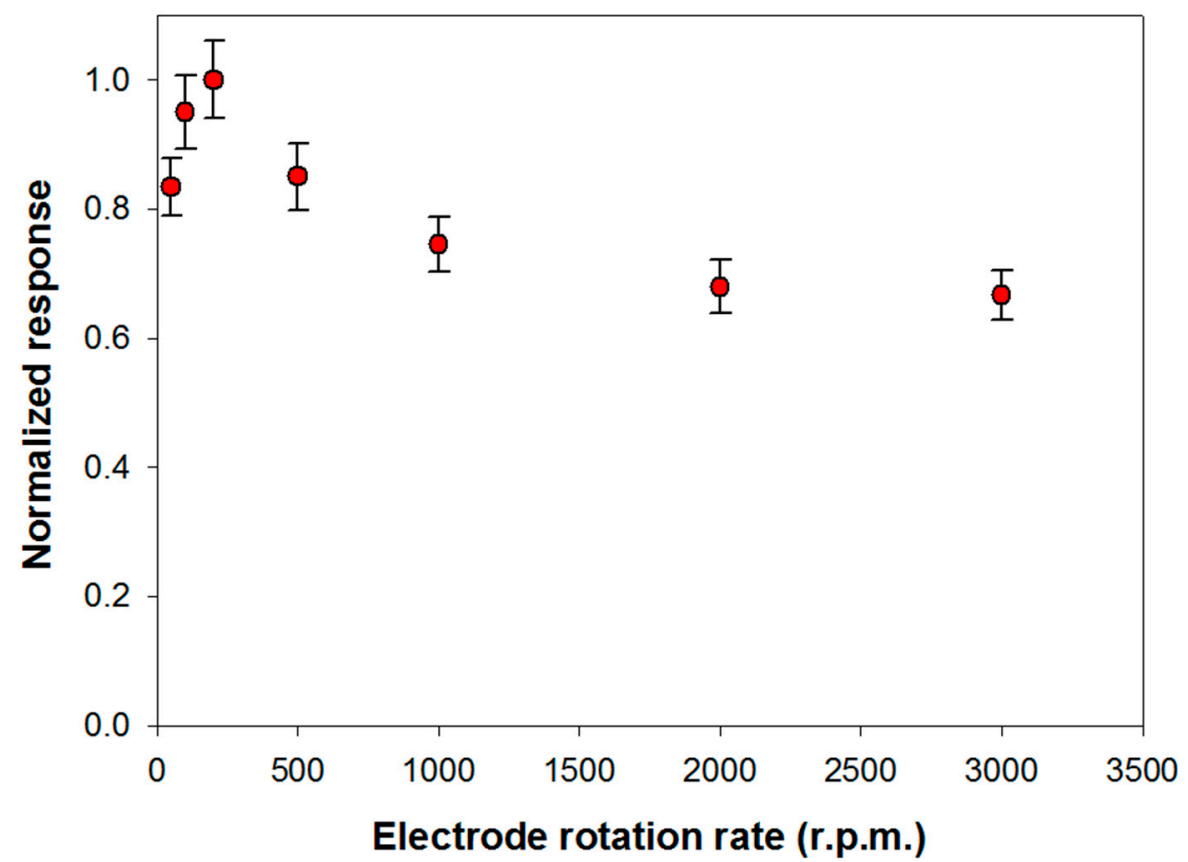

Figure 3. Normalized response (i.e., response/maximum response) of a typical Pt/PPyox/ChO biosensor to PLD $0.22 \mathrm{IU} / \mathrm{mL}$ as a function of electrode rotation rate. Supporting electrolyte: Tris buffer $\mathrm{pH}$ 8.0, I $0.05 \mathrm{M}$ containing $0.75 \%(\mathrm{v} / \mathrm{v})$ Triton X-100, $0.2 \mathrm{mM}$ calcium chloride, and $5 \mathrm{mM}$ phosphatidylcholine. Each value represents the mean of triplicate measurements; the error bars represent the relevant standard deviations.

Particularly, considering that solution stirring promotes the interaction PLD/phosphatidylcholine, the homogeneous catalytic process is unlikely to constitute the rate determining step. The whole bienzymatic process is reasonably controlled by the kinetic of the enzymatic reaction catalyzed by choline oxidase which occurs at the modified electrode. Indeed, the profile at higher rotation rates showed in Figure 3 is similar to that, here not reported, observed when using choline oxidase biosensor for choline sensing. On the other hand, hypothesizing the PLD catalysis in solution as the rate determining step, current signal would have been independent from the rotation rate. This behavior has already been noticed when the same choline biosensor was employed to assay ChE activity in solution following a similar reactions scheme [29].

In conclusion, to assure an appreciable sensitivity under controlled mass transport, a rotation rate of $200 \mathrm{rpm}$ has been adopted in the following experiments.

\subsection{Influence of $\mathrm{pH}$}

Being the proposed method based on the employment of an auxiliary enzyme, i.e., choline oxidase, before optimizing the $\mathrm{pH}$ for PLD assay, the effect of the buffer composition on the response of choline oxidase biosensor was examined using phosphate, glycine, tris, and borate buffers. The results, 
reported in Figure S2 of Supplementary Materials, showed that phosphate and borate buffer allowed to achieve the highest signals. One of the most employed biological buffers is surely Tris which however does not always assure the best analytical results [49]. As a confirmation, in the present study its employment resulted in the lowest response among all the studied buffers. Campanella et al. indeed evidenced a partial inhibition of choline oxidase in Tris buffer [50].

The reaction environment in which the enzymatic hydrolysis of phospholipids containing choline is carried out is usually composed of $50 \mathrm{mM}$ Tris buffer at $\mathrm{pH}$ 8.0, calcium chloride and Triton X-100 [51]. Considering that the response of the choline biosensor was dramatically reduced in Tris buffer, as it was previously showed, the possibility of carrying out PLD assay in alternative buffers has been evaluated. At this aim phosphate, glycine, Tris, HEPES and borate buffers $(0.05 \mathrm{M}, \mathrm{pH} 8.0)$ containing $0.75 \%(\mathrm{v} / \mathrm{v})$ Triton X-100- and 0.2-mM calcium chloride were employed. With the aim to discriminate which buffer allowed high sensitivity while assuring appreciable reproducibility, triplicate assay experiments have been carried out for each investigated system. The mean values of the current slopes with the relevant standard deviations are shown in Figure 4.

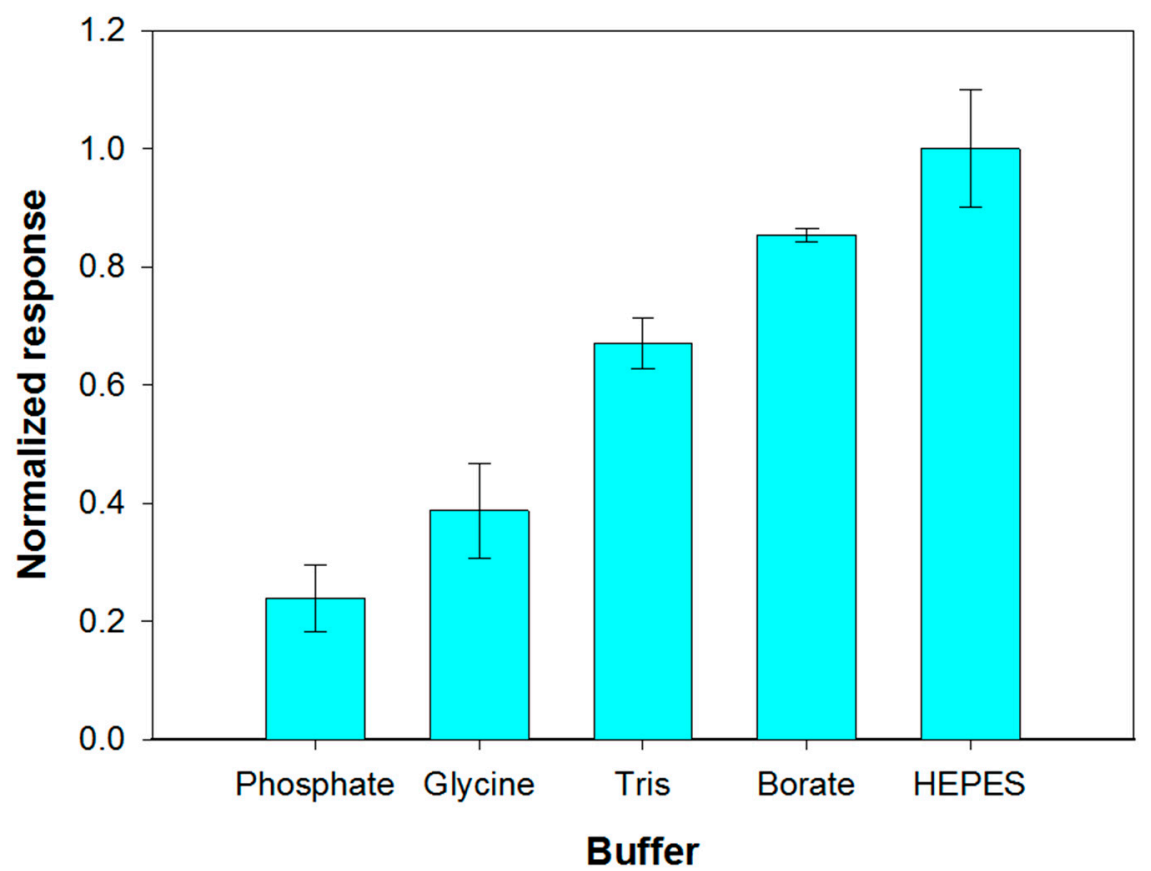

Figure 4. Effect of buffer composition ( $\mathrm{pH} 8.0, \mathrm{I} 0.05 \mathrm{M}$ ) on choline biosensor response to PLD 0.22 IU/mL. Triton X-100 concentration: $0.75 \%(\mathrm{v} / \mathrm{v})$. Calcium chloride concentration: $0.2 \mathrm{mM}$. Phosphatidylcholine concentration: $5 \mathrm{mM}$. Electrode rotation rate: $200 \mathrm{rpm}$. Each value represents the mean of triplicate measurements; the error bars represent the relevant standard deviations.

The best results in term of sensitivity were obtained by employing HEPES and borate buffer. Nevertheless, HEPES buffer provided a poor repeatability of the analytical signal which progressively decreased after successive measurements, as it was already evidenced by Marazuela et al. [45]. Phosphate buffer showed poor reproducibility and sensitivity attributable to precipitation processes at the micromolar calcium concentrations required to maximize PLD activity. Such a buffer was therefore not used even if its employment assured the best performances for choline biosensor (Figure S2). Borate buffer, allowing the best response in terms of both precision (relative standard deviation of $1.3 \%$ $(n=3)$ on intraday measurements) and sensitivity was therefore employed for all further experiments.

The effect of the $\mathrm{pH}$ solution on the analytical signal was then tested within the range 7-9. At this aim the behavior of both the primary enzyme and the auxiliary enzyme upon varying $\mathrm{pH}$ was considered. Preliminary experiments, reported in Figure S3 of Supplementary Material, showed that the maximum sensitivity towards choline of the device $\mathrm{Pt} / \mathrm{PPyox} / \mathrm{ChO}$ falls in the $\mathrm{pH}$ range 8.5-9.5. 
PLD is reported to show in solution a maximum activity at a $\mathrm{pH}$ close to 8.0 [38]. Figure 5 shows the signal slopes variation as a function of $\mathrm{pH}$ at a $\mathrm{Pt} / \mathrm{PPyox} / \mathrm{ChO}$ biosensor upon the addition of phosphatidylcholine $(5 \mathrm{mM})$ and PLD $(0.22 \mathrm{IU} / \mathrm{mL})$. The curve evidences a maximum located at $\mathrm{pH}$ of about 8.0 and therefore in good agreement with the value reported in literature. Subsequent studies have been therefore carried out at $\mathrm{pH} 8.0$ since at this value the activities of both PLD and ChO are almost at maximum.

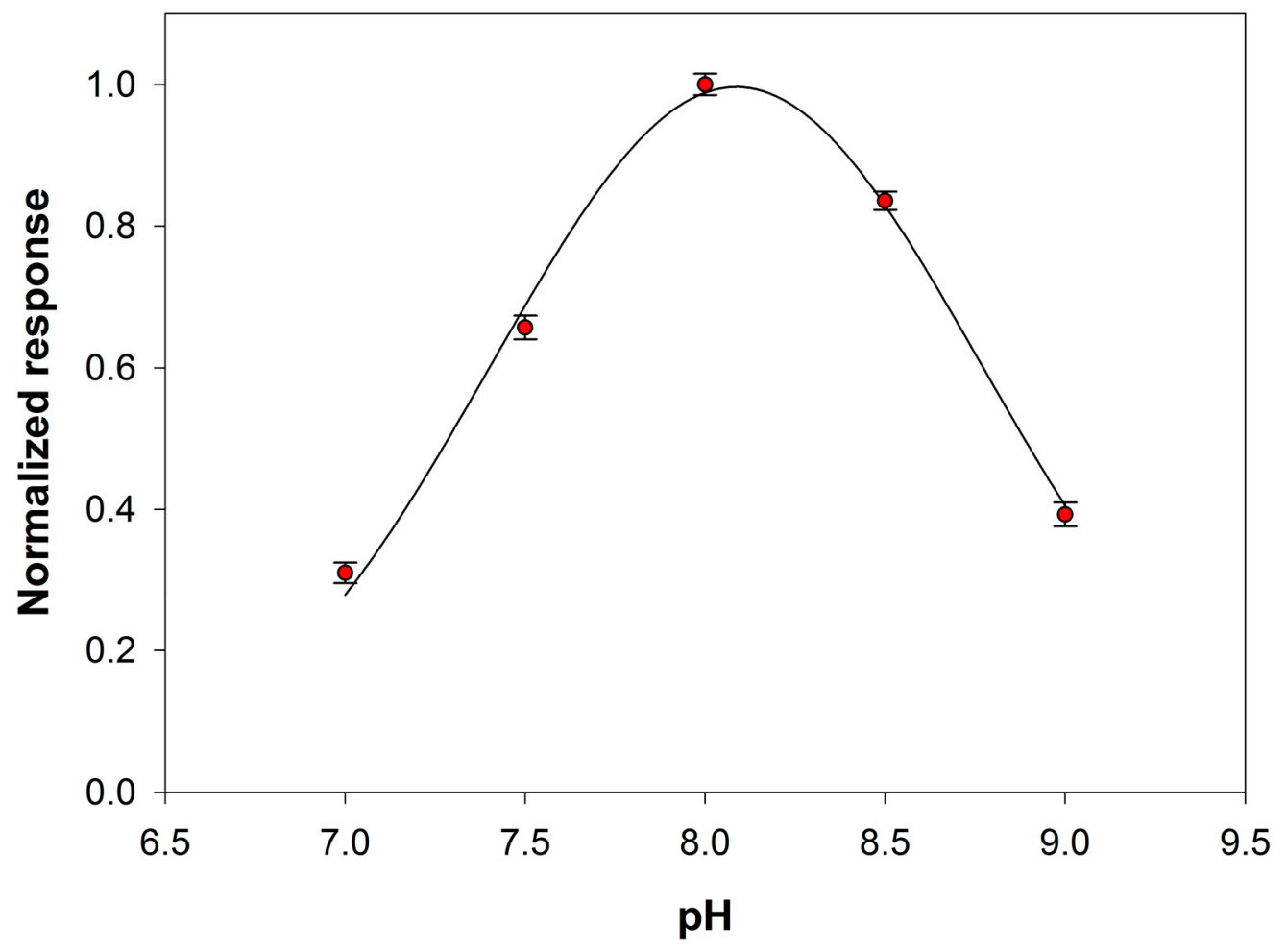

Figure 5. Normalized response (i.e., response/maximum response) of a typical Pt/PPyox/ChO biosensor to PLD $0.22 \mathrm{IU} / \mathrm{mL}$ as a function of $\mathrm{pH}$. Supporting electrolyte: borate buffer $\mathrm{pH}$ 8.0, I $0.05 \mathrm{M}$ containing $0.75 \%(v / v)$ Triton X-100, $0.2 \mathrm{mM}$ calcium chloride, and $5 \mathrm{mM}$ phosphatidylcholine. Electrode rotation rate: $200 \mathrm{rpm}$.

\subsection{Optimization of Substrate Concentration}

PLD from Streptomyces Chromofuscus, like bacterial PLDs in general, has broader substrate specificity than the eukaryotic enzymes. Such an enzyme is able to hydrolyze phosphatidylserine, phosphatidylethanolamine, phosphatidylglycerol, lysophosphatidylcholine, and sphingomyelin. Phosphatidylcholine is considered however the best substrate for hydrolysis. In the present work, L- $\alpha$-phosphatidylcholine from egg yolk was employed with a mean molecular weight of about 768 Da. It is worth noting that complications arise when drawing kinetic data on phospholipases. These enzymes, indeed, acting on water-insoluble substrates, display an enhanced activity when using substrates organized in aggregates. This feature inevitably determines a dependence of the kinetic data on the particular phase in which phospholipids are organized in the reaction mixture. For this reason, we have experimentally verified at which substrate concentration, and then organization, PLD saturation was guaranteed at the experimental conditions already optimized. A calibration graph has been then constructed by varying the phosphatidylcholine concentration realized in the electrolyte solution (borate buffer $\mathrm{pH} 8.0$, I $0.05 \mathrm{M}$ containing $0.75 \%$ Triton X-100, and $0.2 \mathrm{mM} \mathrm{Ca}^{2+}$ ) containing PLD at a concentration of $0.22 \mathrm{IU} / \mathrm{mL}$, and holding the electrode under rotation at a speed of $200 \mathrm{rpm}$.

Figure 6 shows the behavior of the signal current slopes at substrate concentration values ranging from 0.5 to $8 \mathrm{mM}$. As it is possible to see, a phosphatidylcholine concentration of $5 \mathrm{mM}$ assured 
substrate saturation condition for PLD and was therefore adopted to realize the calibration curve for enzyme assay.

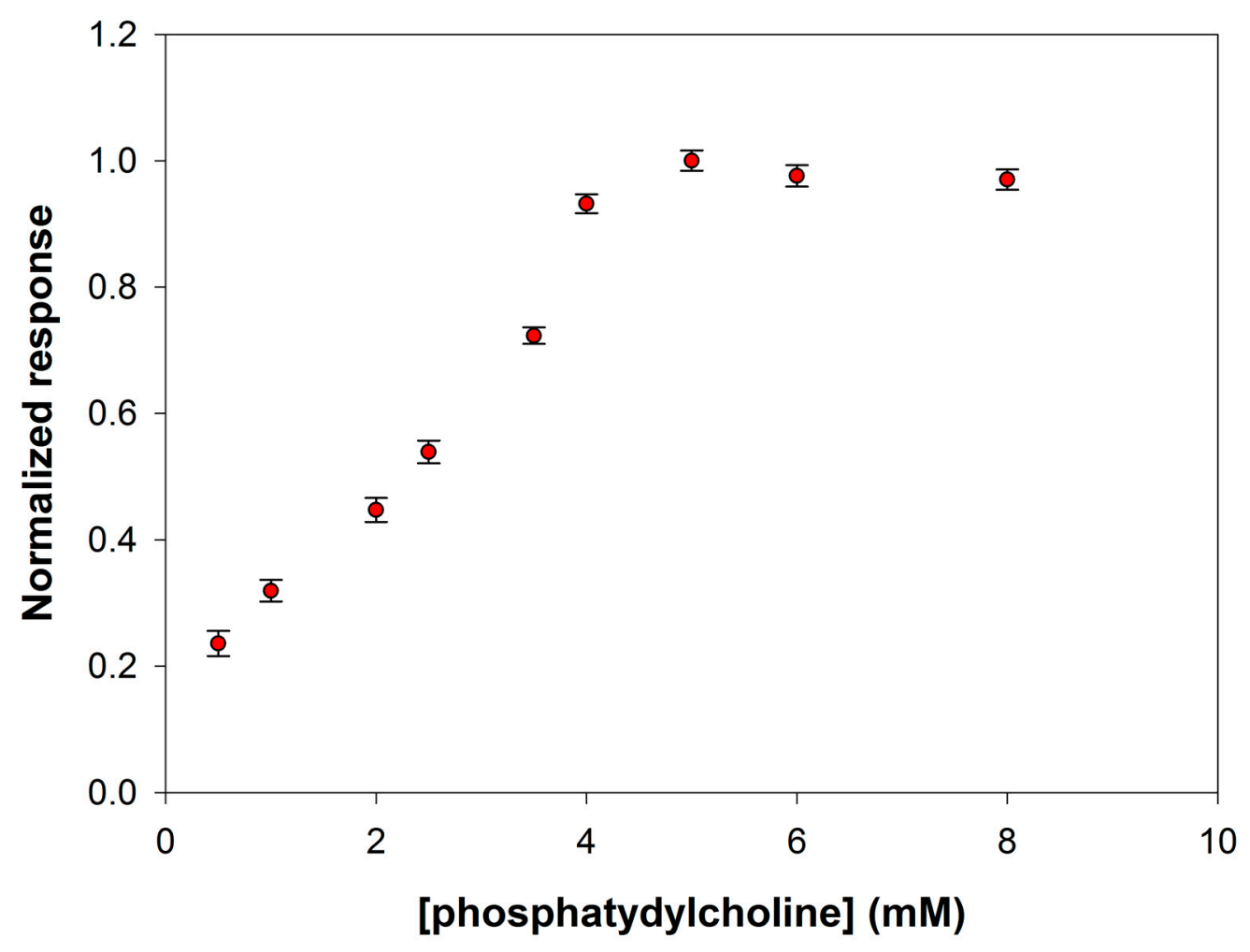

Figure 6. Normalized response (i.e., response/maximum response) of a typical Pt/PPyox/ChO biosensor to PLD $0.22 \mathrm{IU} / \mathrm{mL}$ as a function of phosphatidylcholine concentration. Supporting electrolyte: borate buffer $\mathrm{pH} 8.0$, I $0.05 \mathrm{M}$ containing $0.75 \%$ (v/v) Triton X-100, and $0.2 \mathrm{mM}$ calcium chloride. Electrode rotation rate: $200 \mathrm{rpm}$.

\subsection{Calibration Graphs for PLD Assay}

The calibration curve for PLD assay has been derived by injecting in the electrochemical cell the substrate at the concentration value previously optimized and then by introducing an aliquot of an enzyme standard solution at a fixed temperature of $37^{\circ} \mathrm{C}$. The response has been evaluated, as usual, by the slope of the current signal acquired at the modified electrode. In Figure 7 the calibration graph obtained over all the PLD activities investigated is reported whereas in the inset the linear range of the calibration curve is also illustrated. Fitting of the linear part of the calibration graph gave a regression line with a slope of $23.9 \pm 0.2(\mathrm{nA} / \mathrm{s}) \cdot(\mathrm{IU} / \mathrm{mL})^{-1}$ and an intercept of $(-0.0148 \pm 0.0382)$ $\mathrm{nA} / \mathrm{s}$ (correlation coefficient better than 0.999). Due to the significant accumulation of the enzymatic products during the observation times, a deviation from linearity is observed from an enzyme activity of $0.33 \mathrm{IU} / \mathrm{mL}$. The within-day coefficients of variation for replicate $(n=5)$ PLD assays were $4.15 \%$ and $5.18 \%$ at 0.22 and $0.04 \mathrm{IU} / \mathrm{mL}$ PLD levels, respectively; the between-days $(n=6)$ coefficient of variation was $9.4 \%$ at $0.14 \mathrm{IU} / \mathrm{mL}$ PLD levels. The operational stability of the assay was tested doing replicate PLD assays (at $0.22 \mathrm{IU} / \mathrm{mL}$ PLD level) during a day $(\mathrm{n}=10)$ : the relevant variation was comparable (confidence level of 95\%) with the within-day coefficients of variation so the biosensor response could be considered almost stable. Finally, the long-term stability was proved by evaluating the sensitivity of several calibration curves $(\mathrm{n}=15)$ for PLD assay (at $0.22 \mathrm{IU} / \mathrm{mL}$ PLD level) during an extended period (biosensor stored in buffer at $4{ }^{\circ} \mathrm{C}$ at the dark when not used): after 30 days, the sensitivity dropped to about $25 \%$ of its initial value.

The limit of detection estimated from the linear regression equation was $0.005 \mathrm{IU} / \mathrm{mL}$, corresponding to an absolute amount of $0.03 \mathrm{IU}$ ( $30 \mathrm{nmol}$ of choline per minute). This amount is suitable for practical 
determination of PLD in real samples. As an example, in the clinical field PLD activity in normal mammary cell attests to levels detectable with our device. In mammary carcinoma cell lysate PLD activity was found to be considerable higher with respect to normal cell $(2921.4 \pm 216.7 \mathrm{U} / \mathrm{L}$ vs. $408.6 \pm 28.7 \mathrm{U} / \mathrm{L})[21]$.

A direct comparison with existing PLD assay methods is complicated by the different modalities in which enzyme activity is expressed. Chemiluminescence assays have been reported in which liberation of just 75 pmol of choline per minute was detectable [52]. Method precision was however affected by the presence of substances which react with hydrogen peroxide and proteins at concentrations above $0.2 \%$ $(\mathrm{w} / \mathrm{v})$ which can cause quenching phenomena of the luminol reaction therein employed. Fluorometric detection and radiometric assay are surely highly sensitive techniques $[23,24]$ but need synthetically modified fluorogenic substrates or special equipment to be performed. As concerns the electrochemical method previously described to assay PLD, based on the employment of a choline amperometric biosensor [25], a limit of detection for choline of $0.05 \mathrm{mM}$ was reported and then substantially higher with respect to the value of $0.1 \mu \mathrm{M}$ at $\mathrm{pH} 8$ that we evaluated in our previous work [29]. Moreover, as it was already stressed, the biosensor realization was quite laborious and time consuming [25]. Compared to existing analytical assays, the present method is therefore simple and easy to operate, representing a valid alternative in ascertaining PLD activity in various fields of interest.

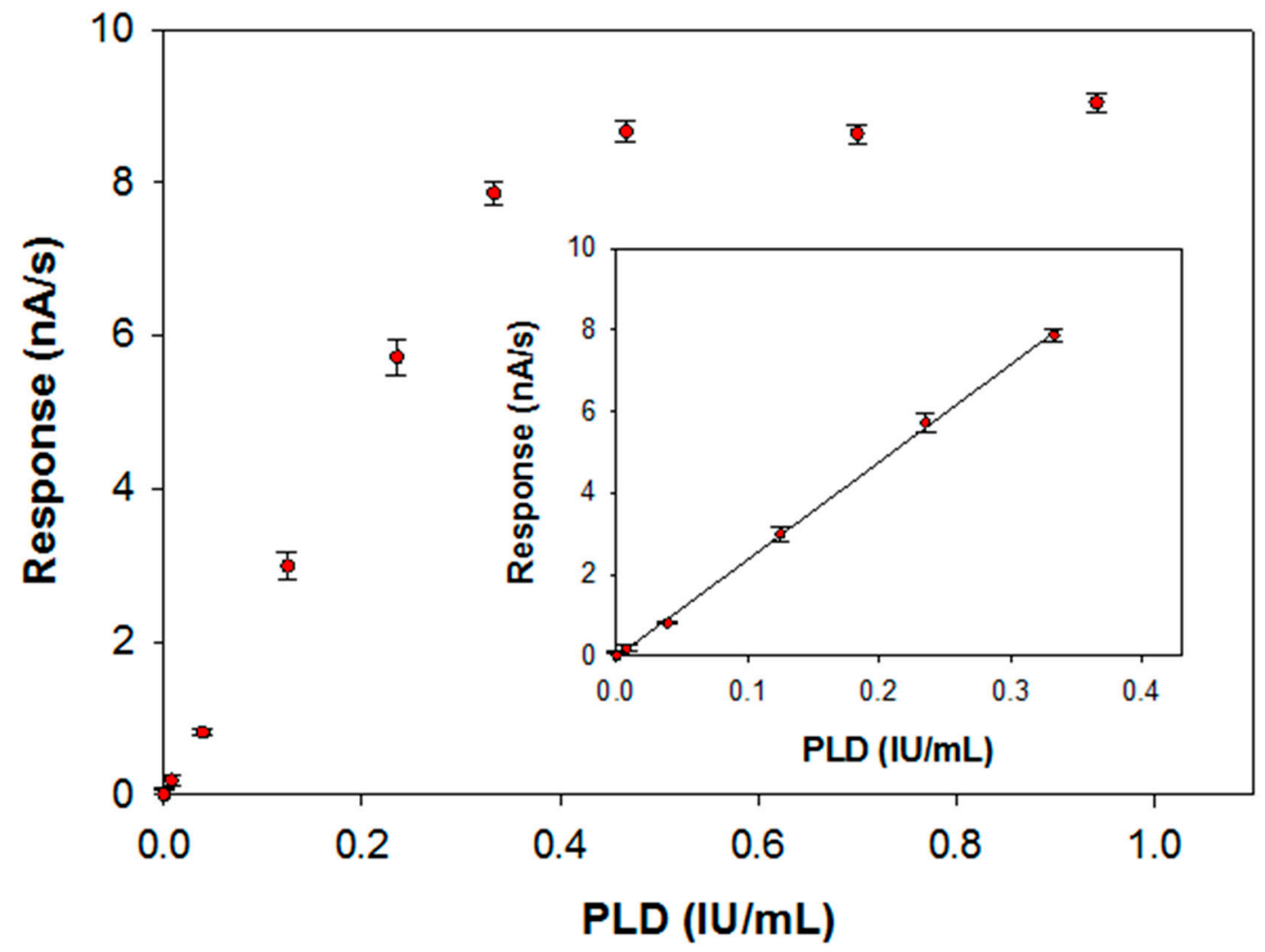

Figure 7. Calibration curve for phosphatidylcholine-PLD system carried out at a typical Pt/PPyox/ChO biosensor. Supporting electrolyte: borate buffer $\mathrm{pH}$ 8.0, I $0.05 \mathrm{M}$ containing $0.75 \%$ (v/v) Triton X-100, $0.2 \mathrm{mM}$ calcium chloride and $5 \mathrm{mM}$ phosphatidylcholine. Electrode rotation rate: $200 \mathrm{rpm}$. Inset: linear interval of the calibration curve.

Preliminary experiments concerning the application of the proposed assay in real samples focused on the determination of PLD activity on crude extracts from pig lung. Lungs were chosen either for its high PLD activity [53] either because its crude extract is surely a complex biological matrix containing endogenous substances (e.g., ascorbate) which can interfere with the present electrochemical assay. Yet, the notable ability of PPyox polymer to reject interfering and fouling species in electrochemical analysis 
ensured proper measurements of PLD activity even in complex matrixes like this. In fact, analysis of pig lung crude extracts, after proper dilution, gave a specific activity of $1.50 \pm 0.08 \mathrm{mIU} / \mathrm{mg}$ which agree with that obtained by the standard colorimetric method (see Materials and Methods section) used here for PLD assay (values from both assays not significantly different at a 95\% confidence level); more importantly, the assay of pig lung crude extracts gave specificity activity values in agreement with those already reported elsewhere [31].

\section{Conclusions}

The novel electrochemical procedure for PLD assay proposed in this work is based on the employment of a bilayer choline biosensor composed of a co-crosslinked choline oxidase coating deposited on a permselective overoxidized polypyrrole film electrosynthesized on a platinum electrode. The optimization of the experimental parameters affecting PLD activity (e.g., $\mathrm{pH}$ and composition of the supporting electrolyte, hydrodynamic conditions, calcium chloride and surfactant concentration) allowed to obtain calibration curves characterized by appreciable sensitivity, wide linear range and adequately low limit of detection. Furthermore, the electrosynthesis of a polymer film with built-in permselectivity could realize a biosensor suitable for real matrices analysis being interferences from endogenous compound, electroactive at the applied potential, minimized. In conclusion, our device proved as an effective and novel method for the determination of PLD activity. Further experiments concerning its application to assay such an enzyme in biological samples are under way in our laboratory.

Supplementary Materials: The following are available online at http://www.mdpi.com/1424-8220/20/5/1304/s1, Section S1: Influence of calcium concentration: ANOVA analysis. Figure S1: Normalized response of a typical $\mathrm{Pt} / \mathrm{PPyox} / \mathrm{ChO}$ biosensor to PLD $0.22 \mathrm{IU} / \mathrm{mL}$ as a function of $\mathrm{Ca}^{2+}$ concentration. Experimental conditions as in Figure 2. Different labels indicate significantly different values. Figure S1: Dependence of the choline biosensor sensitivity on the buffer composition ( $\mathrm{pH} 8.5$, I $0.1 \mathrm{M}$ ). Electrode rotation rate: $1000 \mathrm{rpm}$, Figure S2: Influence of $\mathrm{pH}$ on the response of a typical Pt/PPyox/ChO biosensor. Supporting electrolyte: acetate/phosphate/borate buffer I $0.1 \mathrm{M}$. Electrode rotation rate: $1000 \mathrm{rpm}$.

Author Contributions: Conceptualization, A.G. and R.C.; Investigation, R.C.; Writing—original draft preparation, R.C.; Writing-review and editing, R.C.; Visualization, R.C.; Supervision, A.G.; Project administration, A.G. All authors have read and agreed to the published version of the manuscript.

Funding: The authors gratefully acknowledge financial support from Ministero dell'Istruzione, dell'Università e della Ricerca Italiana.

Acknowledgments: The authors thank Alberto Onzo and Giuliana Bianco for their helpful contribution to the ANOVA analysis. This work comes from Carmela Caivano's thesis.

Conflicts of Interest: The authors declare no conflict of interest.

\section{References}

1. Exton, J.H. Phosphatidylcholine breakdown and signal transduction. Biochim. Biophys. Acta 1994, 1212, 26-42. [CrossRef]

2. Eibl, H.; Kovatchev, S. Preparation of phospholipids and their analogs by phospholipase D. Methods Enzymol. 1981, 72, 632-639.

3. Selvy, P.E.; Lavieri, R.R.; Lindsley, C.W.; Brown, H.A. Phospholipase D: Enzymology, Functionality, and Chemical Modulation. Chem. Rev. 2011, 111, 6064-6119. [CrossRef] [PubMed]

4. Foster, D.A.; Xu, L. Phospholipase D in cell proliferation and cancer. Mol. Cancer Res. 2003, 1, 789-800. [PubMed]

5. Ryu, S.B.; Wang, X. Expression of Phospholipase D during Castor Bean Leaf Senescence. Plant Physiol. 1995, 108, 713-719. [CrossRef] [PubMed]

6. Ella, K.M.; Dolan, J.W.; Chen, Q.; Meier, K.E. Characterization of Saccharomyces Cerevisiae deficient in expression of phospholipase D. Biochem. J. 1996, 314, 15-19. [CrossRef] 
7. McNamara, P.J.; Cuevas, W.A.; Songer, J.G. Toxic phospholipases D of Corynebacterium pseudotuberculosis, C. ulcerans and Arcanobacterium haemolyticum: Cloning and sequence homology. Gene 1995, 156, 113-118. [CrossRef]

8. Juneja, L.R.; Kazuoka, T.; Goto, N.; Yamane, T.; Shimizu, S. Conversion of phosphatidylcholine to phosphatidylserine by various phospholipases D in the presence of L- or D-serine. Biochim. Biophys. Acta 1989, 1003, 277-283. [CrossRef]

9. D'Arrigo, P.; Servi, S. Using phospholipases for phospholipid modification. Trends Biotechnol. 1997, 15, 90-96.

10. Kanaho, Y.; Nakai, Y.; Katoh, M.; Nozawa, Y. The phosphatase inhibitor 2,3-diphosphoglycerate interferes with phospholipase D activation in rabbit peritoneal neutrophils. J. Biol. Chem. 1993, 268, 12492-12497.

11. Morris, A.J.; Frohman, M.A.; Engebrecht, J. Measurement of Phospholipase D Activity. Anal. Biochem. 1997, 252, 1-9. [CrossRef] [PubMed]

12. Fezza, F.; Gasperi, V.; Mazzei, C.; Macarrone, M. Radiochromatographic assay of N-acyl-phosphatidylethanolamine-specific phospholipase D activity. Anal. Biochem. 2005, 339, 113-120. [CrossRef] [PubMed]

13. Lambrecht, R.; Ulbrich-Hofmann, R. A facile purification procedure of phospholipase D from cabbage and its characterization. Biol. Chem. Hoppe-Seyler 1992, 373, 81-88. [CrossRef]

14. Ikarashi, Y.; Maruyama, Y. Liquid chromatography with electrochemical detection for quantitation of bound choline liberated by phospholipase D hydrolysis from phospholipids containing choline in rat plasma. J. Chromatogr. B 1993, 616, 323-326. [CrossRef]

15. Majd, S.; Yusko, E.C.; MacBriar, A.D.; Yang, J.; Mayer, M. Gramicidin pores report the activity of membrane-active enzymes. J. Am. Chem. Soc. 2009, 131, 16119-16126. [CrossRef] [PubMed]

16. Do, L.D.; Buchet, R.; Pikula, S.; Abousalham, A.; Mebarek, S. Direct determination of Phospholipase D activity by infrared spectroscopy. Anal. Biochem. 2012, 430, 32-38. [CrossRef] [PubMed]

17. Thevenot, C.; Daussant, J.; Kas, J.; Valentova, O. Sensitive techniques for Phospholipase D determination in plants. Trends Anal. Chem. 1993, 12, 266-271. [CrossRef]

18. Hergenrother, P.J.; Haas, M.K.; Martin, S.F. Chromogenic assay for phospholipase D from Streptomyces chromofuscus: Application to the evaluation of substrate analogs. Lipids 1997, 32, 783-788. [CrossRef] [PubMed]

19. D'Arrigo, P.; Piergianni, V.; Scarcelli, D.; Servi, S. A spectrophotometric assay for phospholipase D. Anal. Chim. Acta 1995, 304, 249-254.

20. Liu, S.-J.; Wen, Q.; Tang, L.J.; Jiang, J.H. Phospholipid-graphene nanoassembly as a fluorescence biosensor for sensitive detection of Phospholipase D Activity. Anal. Chem. 2012, 84, 5944-5950. [CrossRef] [PubMed]

21. Cen, Y.; Wu, Y.-M.; Kong, X.-J.; Wu, S.; Yu, R.-Q.; Chu, X. Phospholipid-modified upconversion nanoprobe for ratiometric fluorescence detection and imaging of Phospholipase D in cell lysate and in living cells. Anal. Chem. 2014, 86, 7119-7127. [CrossRef] [PubMed]

22. Zhu, X.; Fan, L.; Wang, S.; Lei, C.; Huang, Y.; Nie, Z.; Yao, S. Phospholipid-tailored titanium carbide nanosheets as a novel fluorescent nanoprobe for activity assay and imaging of phospholipae D. Anal. Chem. 2018, 90, 6742-6748. [CrossRef] [PubMed]

23. Dippe, M.; Ulbrich-Hofmann, R. Spectrophotometric determination of phosphatidic acid via iron (III) complexation for assaying Phospholipase D activity. Anal. Biochem. 2009, 392, 169-173. [CrossRef] [PubMed]

24. Rahier, R.; Noiriel, A.; Abousalham, A. Development of a direct and continuous Phospholipase D assay based on the chelation-enhanced fluorescence property of 8-hydroxyquinoline. Anal. Chem. 2016, 88, 666-674. [CrossRef] [PubMed]

25. Vrbová, E.; Kroupová, I.; Valentová, O.; Novotná, Z.; Káš, J. Determination of Phospholipase D activity with a choline biosensor. Anal. Chim. Acta 1993, 280, 43-48.

26. Guerrieri, A.; Ciriello, R.; Cataldi, T.R.I. A novel amperometric biosensor based on a cocrosslinked 1-lysine- $\alpha$-oxidase/overoxidized polypyrrole bilayer for the highly selective determination of l-lysine. Anal. Chim. Acta 2013, 795, 52-59. [CrossRef] [PubMed]

27. Ciriello, R.; Cataldi, T.R.I.; Crispo, F.; Guerrieri, A. Quantification of 1-lysine in cheese by a novel amperometric biosensor. Food Chem. 2015, 169, 13-19. [CrossRef]

28. Ciriello, R.; De Gennaro, F.; Frascaro, S.; Guerrieri, A. A novel approach for the selective analysis of L-lysine in untreated human serum by a co-crosslinked L-lysine- $\alpha$-oxidase/overoxidized polypyrrole bilayer based amperometric biosensor. Bioelectrochemistry 2018, 124, 47-56. [CrossRef] 
29. Ciriello, R.; Lo Magro, S.; Guerrieri, A. Assay of serum cholinesterase activity by an amperometric biosensor based on a co-crosslinked choline oxidase/overoxidized polypyrrole bilayer. Analyst 2018, 143, 920-929. [CrossRef]

30. Guerrieri, A.; De Benedetto, G.E.; Palmisano, F.; Zambonin, P.G. Amperometric sensor for choline and acetylcholine based on a platinum electrode modified by a co-crosslinked bienzymic system. Analyst 1995, 120, 2731-2736. [CrossRef]

31. Okamura, S.; Yamashita, S. Purification and Characterization of Phosphatidylcholine Phospholipase D from Pig Lung. J. Biol. Chem. 1994, 269, 31207-31213. [PubMed]

32. Centonze, D.; Guerrieri, A.; Malitesta, C.; Palmisano, F.; Zambonin, P.G. Interference-free glucose sensor based on glucose-oxidase immobilized in an overoxidized non-conducting polypyrrole film. Fresen. J. Anal. Chem. 1992, 342, 729-733. [CrossRef]

33. Guerrieri, A.; Palmisano, F. An Acetylcholinesterase/Choline Oxidase-Based Amperometric Biosensor as a Liquid Chromatography Detector for Acetylcholine and Choline Determination in Brain Tissue Homogenates. Anal. Chem. 2001, 73, 2875-2882. [CrossRef] [PubMed]

34. Guerrieri, A.; Lattanzio, V.; Palmisano, F.; Zambonin, P.G. Electrosynthesized poly(pyrrole)/poly(2-naphthol) bilayer membrane as an effective anti-interference layer for simultaneous determination of acethylcholine and choline by a dual electrode amperometric biosensor. Biosens. Bioelectron. 2005, 21, 1710-1718. [CrossRef]

35. Guerrieri, A.; Ciriello, R.; Crispo, F.; Bianco, G. Detection of choline in biological fluids from patients on haemodialysis by an amperometric biosensor based on a novel anti-interference bilayer. Bioelectrochemistry 2019, 129, 135-143. [CrossRef]

36. Shimbo, K.; Yano, H.; Miyamoto, Y. Two Streptomyces strains that produce phospholipase D with high transphosphatidylation activity. Agric. Biol. Chem. 1989, 53, 3083-3085. [CrossRef]

37. Carrera, G.; D’Arrigo, P.; Piergianni, V.; Roncaglio, S.; Secondo, F.; Servi, S. Purification and properties of two phospholipases D from Streptomyces species. Biochim. Biophys. Acta 1995, 1255, 273-279. [CrossRef]

38. Imamura, S.; Horiuti, Y. Purification of Streptomyces chromofuscus Phospholipase D by hydrophobic affinity chromatography on palmitoyl cellulose. J. Biochem. 1979, 85, 79-95. [CrossRef] [PubMed]

39. Roberts, M.F. Assays of phospholipases on short-chain phospholipids. Methods Enzymol. 1991, 197, $95-112$. [PubMed]

40. Dennis, E.A. Kinetic dependence of phospholipase activity on the detergent Triton X-100. J. Lipid Res. 1973, 14, 152-159. [PubMed]

41. Holbrook, P.; Pannell, L.K.; Daly, J.W. Phospholipase D-catalyzed hydrolysis of phosphatidylcholine occurs with PO bond cleavage. Biochim. Biophys. Acta 1991, 1084, 155-158. [CrossRef]

42. Reynolds, L.J.; Washburn, W.N.; Deems, R.A.; Dennis, E.A. Assay strategies and methods for phospholipases. Methods Enzymol. 1991, 197, 3-23. [PubMed]

43. Yang, H.; Roberts, M.F. Cloning, overexpression, and characterization of a bacterial $\mathrm{Ca}^{2+}$ dependent phospholipase D. Protein Sci. 2002, 11, 2958-2968. [CrossRef] [PubMed]

44. Heller, M.; Greenzaid, P.; Lichtenberg, D. The activity of phospholipase D on aggregates of phosphatidylcholine, dodecylsulfate and $\mathrm{Ca}^{2+}$. Adv. Exp. Biol. 1978, 101, 213-220.

45. Marazuela, M.D.; Moreno-Bondi, M.C. Determination of choline-containing phospholipids in serum with a fiber-optic biosensor. Anal. Chim. Acta 1998, 374, 19-29. [CrossRef]

46. Yamamoto, I.; Konto, A.; Handa, T.; Miyajima, K. Regulation of phospholipase D activity by neutral lipids in egg-yolk phosphatidylcholine small unilamellar vescicles and by calcium ion in aqueous medium. Biochim. Biophys. Acta 1995, 1233, 21-26. [CrossRef]

47. Kirat, K.E.; Besson, F.; Prigent, A.F.; Chauvet, J.P.; Roux, B. Role of calcium and membrane organization on phospholipase D localization and activity. Competition between a soluble and an insoluble substrate. J. Biol. Chem. 2002, 277, 21231-21236. [CrossRef]

48. Bartlett, P.N.; Whitaker, R.G. Electrochemical immobilisation of enzymes: Part I. Theory. J. Electroanal. Chem. 1987, 224, 27-35. [CrossRef]

49. Perrin, D.D.; Dempsey, B. Buffers for $p H$ and Metal Ion Control; Chapman \& Hall: London, UK, 1974.

50. Campanella, L.; Mascini, M.; Palleschi, G.; Tomassetti, M. Determination of choline-containing phospholipids in human bile and serum by a new enzyme sensor. Clin. Chim. Acta 1985, 151, 71-83. [CrossRef]

51. Takayama, T.; Itoh, S.; Nagasaki, T.; Tanimizu, I. A new enzymatic method for determination of serum choline-containing phospholipids. Clin. Chim. Acta 1977, 79, 93-98. 
52. Becker, M.; Spohn, U.; Ulbrich-Hofman, R. Detection and Characterization of Phospholipase D by Flow Injection Analysis. Anal. Biochem. 1997, 244, 55-61. [CrossRef] [PubMed]

53. Wang, P.; Anthes, J.C.; Siegel, M.I.; Egan, R.W.; Billah, M.M. Existence of cytosolic phospholipase D. Identification and comparison with membrane-bound enzyme. J. Biol. Chem. 1991, 266, 14877-14880. [PubMed]

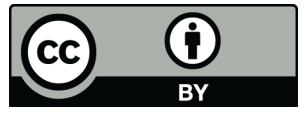

(C) 2020 by the authors. Licensee MDPI, Basel, Switzerland. This article is an open access article distributed under the terms and conditions of the Creative Commons Attribution (CC BY) license (http://creativecommons.org/licenses/by/4.0/). 